\title{
On Essential Design
}

\author{
Shizhong Nie \\ Art and Design Department \\ Shaoyang University \\ Shaoyang, China
}

\begin{abstract}
Art design is a purposeful aesthetic creation activity of human beings, a kind of intelligent culture creation activity of subjective objectification and problem solving, and a creation process of new symbols. Design is a kind of life management based on human beings and self decoration of human themselves with initiative survival nature. Design is born for human, provides services for human and satisfies people's need. Design uses art to create new material symbols and change people's life. Design is advanced productivity creating high added value for commodities. It is also a production management means determining enterprise's survival and development.
\end{abstract}

\section{Keywords—design; essence}

\section{INTRODUCTION}

In 1980s and 1990s, the meaning of "design" is basically included in "wide art" and China's art design uncovers a new chapter under the influence of " 85 " thought trends of art. Along with economic reform, art design actively gets into the swing of social culture and absorbs cultural and artistic ideas of western modernism. At the same time, China's economic reform background provides a great stage for art design. Many art designers pursue new styles of art design to their hearts' content and display new tide, fashion and even vanguard in new architecture, fashion show and packaging advertisement design. Through constant evolution and reproduction, art design has formed a wide culture basis in China and it becomes an important subject. In 1998, art design subject is changed into art design from "applied arts" in General Institutes of Higher Education Undergraduate Program Catalog of Ministry of Education. In 2011, art theory's subject category is enhanced by Academic Degrees Committee of the State Council, thus design becomes an individual subject in art and becomes parallel with fine arts officially.

At the same time, a lot of books of design art theory compiled by Wang Shouzhi, Yin Dingbang, Zhang Daoyi, Li Yanzu, Li Lixin, Xia Yanjing, Hang Jian, Zhang Fuye, Zhao Nong, Zhao Jianghong, Jing Lei, Chen Zhengjun, Wu Tingyu, Dong Zhanjun, Yang Xianyi, Li Jiang, He Renke, Zhu Heping and so on establish theoretical subject of art design. However, research works concerning design essence build their own array individually without a uniform target system. Because design is an interdisciplinary subject, the three-dimensional research of which is not formed yet. At present, research material of China's design history is mostly about art history

This paper is one of the stage results of Hunan province general institutes of higher education's teaching reform project-Application of DiscussionBased Teaching in Art Design Theoretical Course(Xiang Jiao Tong [2015]291). and technology history. Numerous subject achievements of technology, psychology, mechanical engineering, electronic economics, mathematics and chemistry have not well entered the sight of design theory researchers.

Design stretches across liberal arts and science and it belongs to comprehensive interdisciplinary subject. Therefore, at present, scholars' understanding of design essence is mainly as follows.

- Design is imagination and planning.[1]

- The so-called design refers to a method solving planning, programming, envisage and problems and a visual process conveyed through sight.[2]

- Design is a problem solving activity around the target.[3]

- Simon, a Nobel Prize winner and a managerialist, thinks "Design is people-oriented".[4]

- Gionis thinks: Design is an activity to express a kind of pure belief.[5]

- In Re-discussion on Modern Engineering Education, Lu Yongxiang thinks "Design is to satisfy social needs in a most reasonable way with certain restricted conditions".[6]

- Design is crossing from objective reality to future possibly with imagination.[7]

- Deere Knot thinks "Design is a kind of social and cultural activity."[8]

\section{EXPLANATION OF “DESIGN" IN CHINESE AND FOREIGN HISTORY}

Meaning of "design" in Modern Chinese Dictionary: Draft strategies and patterns in advance before officially doing a certain task according to specific purpose and requirement.[9]

In ancient Chinese documents, the concept similar to ancient western "design" is "management".

Daming Palace, West Inner Courtyard, Yeting Palace, Taiji Palace, East Palace, Imperial City, West Market, East Market, Hibiscus Pool. "Fig. 1" 


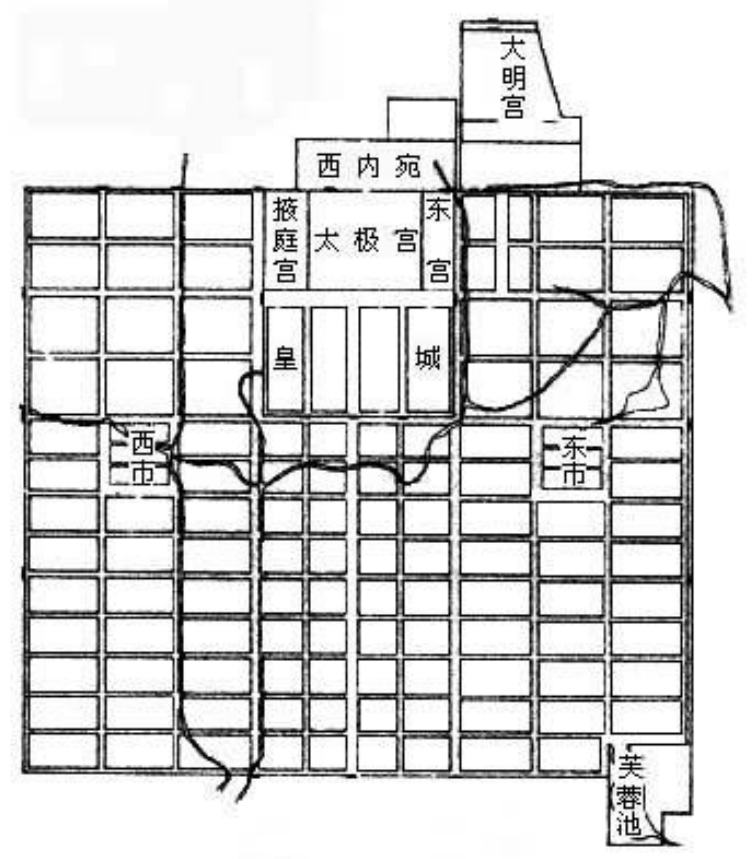

唐长安城复原示意图

Fig. 1. Sketch Map of Chang'an of Tang Dynasty

Tracing back to ancient China, we can find etymology of design, such as "Laying out the ground work of Lingtai platform and busily planning and designing" in Poetry - Elegance - Lingtai, and "drafting of painted works, paintings, silk, bell, basket and heavy curtain" in Rites of Zhou - Kaogong Ji. "She" here means "drafting and planning". "Weather is limited by seasons, land is limited by climate, and there are both good and bad craftsmen and materials. It is best to combine the above four aspects. Craftsmen build the capital into a square with each side of nine li long. There are three gates on each side. There are nine north-south roads and nine east-west roads in the capital, with each road holding nine vehicles at the same time. Outside the palace, temples are on the left side and altar of land and grain is on the right side. The court is in front of the imperial palace and the market is behind the north palace." Kaogong Ji firstly puts forward simple process view and capital design system. This handicraft work is conclusion of human's design experience in early period. It can also be regarded as the initial sprout and starting point of design as a theory. It summaries scientific experience of ancient China's various production process. What's more precious is that it is not only the theoretical and systematical summary of that period, but also the basic principle for today's production process.

In Guanzi Quanxiu, there is "Making a plan for the whole year fails to compete with people planting crops; making a plan for a decade fails to compete with people planting trees; Making a plan for the whole life fails to compete with people cultivating talents." The "Ji" here has the meaning of "design". In Warriors of Fate Wei Zhi, there is "Bribing people around me to take medicine containing dove poison as a plot". "Sheji" here means making a plot. In Xie He's Six Principles of
Chinese Painting of the Southern Qi dynasty, there is a principle of "Management depends on location". In the Elegance of Bamboo and Spring - Painting Skill of Northern Song dynasty, Guo Xi and Guo Si point out "Management should conform to heaven and earth". In Zhou Yigui's Mountain Picture Copybook - Before and After Six Principles of Qing dynasty, there is "In terms of six principles, management location should come first." In Zhang Yanyuan's Famous Paintings of History of Tang dynasty, there is "Management location is the scheme of painting." Zhang Yanyuan shows meaning of design in Chinese art through reelaboration of Xie He's "six principles". "Management" forms coreference with "layout", "structure" and "composition" in ancient literary theory, calligraphy theory and painting theory. Its connotation is similar to "design" in modern Chinese language. In "Entrusting planning and scheme to Zhang Liang and entrusting appointing a general to finish his apprenticeship to Han Xin", the "Sheji" here means scheming(The first section of Shang Zhongxian's Qi Ying Bu of Yuan dynasty). In Du Fu's Dan Qing Yin of Tang dynasty, there is "Paintings of meritorious statesman in Lingyan pavilion fade in color as years go by. General Cao's repainting makes it spectacular. The emperor orders you to unfold tiffany to prepare for painting and you exercise your inventive mind, manage gloomily and make great efforts." The "Yijiang" here refers to $\mathrm{Cao} \mathrm{Ba}$ 's design concept at the beginning of painting. In "How many golds cast into management of design concept", a sentence from a poem of Zhao Yi in Qing dynasty to the owner of Wang Shi Yuan Garden after he visits it, the "Yijiang" here also means design or construction.

Design has two meanings in ancient Chinese: The first meaning is main means and mode of governing country concepts. The second one is design's functional factors of formation and psychological category, displaying design's functional purpose and aesthetic effect.

As a foreign word, "design" is introduced to China as the meaning of "pattern" or "industrial art" in earlier period of last century. Since last century, Chinese "Sheji" has experienced at least three times of changes: namely pattern - industrial art design art. Changes of three names prove that people have different understandings of "design" in different periods. In Newest Design Method (China's first design technique monograph), Yu Jianhua mentions the word of design: Although it begins to sprout in China, there are few people well knowing its meaning and painting techniques. Since Chinese people want to develop industry by improving commodity quality to compete with foreign countries in the east and west, there is no time to delay in devoting particular care to pattern. No matter it is art craft or daily device, if you want to make an object, firstly you should have a pattern for it. Craft and pattern can not do without each other for even a moment. The "pattern" here obviously refers to plain ornamentation and stereo design drawing and model program.

As the first person promoting "aesthetic education" in China, Cai Yuanpei is also the person putting forward "applied art" at the earliest. In Origin of Art, he mentions that: "Art is both narrow and generalized. In narrow sense, it exclusively refers to architecture, statue (engraving), painting and applied art and so on. The "applied art" here reflects era thought and 
life style in the society. It emphasizes on researching aesthetic evolution of human being's articles for daily use and production development history. Applied art emphasizes on researching the process of production and manufacturing and the important role of material, technology and manufacturing. In 1930s, Liu Lin appeals "Industrial products from Europe, America and Japan enter China in great quantities mostly because they emphasize on design. Namely they emphasize on the form and quality of products which have a low price and great functions. On the contrary, Chinese products have ugly forms. It is obviously because that China's manufacturers and industrialists neglect the importance of applied art and fail to regard applied art as the necessary tool for commodity competition."

In Great Britain Version Encyclopedic (Version1786), "design" is explained as: "coordination of art work's line and shape in proportion, dynamic and aesthetic aspect. In this sense, 'design' has the same meaning with constitution and people can think in aspects of plain, stereo, color, structure and outline composition". In this sense, "design" is endowed with aesthetic meaning and it is mentioned in the same breath with "pattern" which has extremely strong decorative sense. The meaning of design in this period is still limited in relatively narrow scope of "art works". Later on, with arrival of largescale machine industrialization, concept and meaning of "design" step out from pure artistic scope of "art works" and tend to be wide. Design mainly refers to plan, scheme and conception in making a certain kind of creation. In a general sense, it refers to producing an effective entirety, partial adjustment and confirmation of relevant structure and details. Namely, it is the concept of design in a broad sense.

In Oxford Dictionary, "design" is divided as both a noun and a verb. As a noun, it mainly refers to mental planning and drawing preliminary sketch. The fifth version Great Britain Encyclopedic(Concise Britain Encyclopedic) published by encyclopedia of China publishing house in 1974 (Version 1986) explains "design" as: In art, design usually refers to the process of making a plan and specifically refers to a specific plan in mind or on a preliminary sketch or of a mode. Product patter design is applied art work. In art, design itself is a kind of creation process. In architectural process, design is only simple recording reflecting proper concept and experience. In architectural engineering and product design, art and craft tend to permeate. Namely, architectural designer, craft worker, drawer or applied art designer can neither design just according to formula nor play freely like painters, poets or musicians. In various arts and art teaching aspect, design has a broad meaning with respect to composition of a picture, style and decoration. When being used as composition of a picture, design refers to the system of various inner relations of objects.

\section{ESSENCE AND SIGNIFICANCE OF DESIGN}

\section{A. Design Comes from Life}

Design comes from life and gets back to life. From clothes and foods, trademark, city construction to aircraft carrier and spacecraft, almost everything around us is closely related to design. Design brings convenience to people's life. Design is a systematic project, involving human beings, society, environment and so on. A country's development strategy needs firstly accomplishment of design. Various art designs and various products' exterior and package influence you and your choice all the time. Artistic beauty of design is everywhere. Design creation pushes forward development of people's life style and changes people's living space. There will be no life and creative spirit in built environment, industrial product, decorative advertising, animation, apparel, enterprise image and other aspects without successful designs.

Art design belongs to applied art and it takes art as the requirement and ingredient of design to exist in human being's creation history and involves each aspect of basic necessities of life. It has different art forms in different design varieties with artistic manifestation mode and its essence is combination of utility and aesthetic appreciation. The most basic and most important creative activity in people's laboring practice is creation. The advanced plan in creation activity is "design". Just like we usually say "using one's head", "brain storm" and "finding out the secret to success", design refers to programming, planning, management and assumption. Design is a kind of creative activity conducted to realize a certain purpose. In essence, design's sociality is superior to its culturing. The former derives from combination of relevant economic benefit of daily necessities' production.

\section{B. Design Is a Kind of Life Management Based on Human Being}

Labor creates everything. After appearance of "people who are able to create tools", main purpose of design is to serve people. People rely on creation activities to change themselves. Design is people's self decoration with active survival nature and it is materialization process of subjective consciousness. It is also a process of displaying ideas clearly through a specific way or means. As a kind of creation, design refers to art designers using fashioned appearance to act on people's vision and conveying with the help of visual art image resources. Design image well displays its special conveying mode and can quickly win favor in the era of image-reading.

Vasari points out: "Design is the father of three kinds of art (architecture, painting and sculpture"[10]. In the four links of design-production-sales-use, design comes first and decides direction of the following three links.

Original fresco is a way by which ancient people wish to connect with supernaturalism. It is probably the words ancient people say to their adoring gods. This is the earliest art design sense of human being, namely the so-called "a significant form" of Bell[11].

\section{Design Is a Kind of Aesthetic Appreciation Activity}

The concept of "design" is born in Italy in the renaissance period and gets mature in Germany in Bauhaus period. It can be said that the concept of "design" (disegno) gets developed as a term of art criticism in Italy in the renaissance period. Renaissance gives birth to sketch, chromatics, perspective science and anatomy. Today's "design" is referred to as "sketch" in the renaissance period, namely reasonable arrangement of visual art element and basic principles. Aesthetic appreciation activity of design is displayed in 
materialization process of human beings' concept. The finality and foreseeability of design is a kind of problem-solving activity. It is presentation of creating new symbols. Aesthetic taste and ideal are generated in this kind of intelligent cultural creation activity-aesthetic activity. Aesthetic idea is a specific product of human beings' spiritual activities. Aesthetic value reflected by design aesthetics is a multicomponent whole. Design is a kind of intensive creative activity with knowledge and wisdom as its tools. The purpose is to improve people's living quality and create a kind of more beautiful humannature-society environment.

\section{Design Has Contemporaneity}

Design's contemporaneity character entitles design results with stigma of different eras, societies, time and space. Design becomes more and more professional and exclusive. People's life style determines their creative activities. The purpose, content, means and whole design idea of design can not do without specific social productivity condition and corresponding human beings' life style.

In agricultural society, production mode is mainly manual labor and life style is slow and inefficient. Depending on diversified and individualized production mode of small quantity, design gives birth to traditional handicraft design. In industrial society, production mode is mainly mechanization and life style is quick, efficient and open, thus modern design based on mass production of machine comes into being. Life style, social production and operation mode of information society determine design of the information age. In postmodern information society, the object, means, form and design thinking of design have huge changes. In information society, people's need in material, spirit and culture layer gets diversified with diversification of life style and ideology, therefore design becomes diversified. No matter it is which era, the ultimate purpose of design-the objective of design serving people will never change.

\section{E. Ultimate Purpose of Design Is Designing for "People" and Design Has Utilitarian}

Firstly, people researched in design have physiological characteristics of a material person, like ergonomics, human body metrology, anatomy and behavioristics. All these need to be researched by design. Also, design needs to research the relation between object and environment, like materials science, environmental protection, tectonics and so on and how to form harmony between object and environment to conform to people's survival need. In addition, design needs to research object's circulation mode, like advertisement display, display design, packaging decoration and so on.

Modern people depend more and more on usage of various tools: When they go out, there is car, train and plane. They do not take much cash with them. There are more and more various bank cards. They use computers and telephones to communicate. Only when "object" and "person" have relation, can the "object" here be called "machine". The more specific directivity of man-machine relationship, it is more helpful for our design analysis. "People oriented" is one of the most popular vocabularies in design field. Some scholars try dividing "people" into "human desire", "human nature" and "humanity" from "vertical domain" of "human" and think that human desire derives from people's physiological defect or deficiency. Therefore, "human desire" is in a lower level of design. "Human nature" is people's nature of "pursuit of happiness", reflecting people's spiritual need. Therefore, it is in the senior level of design. "Humanity" is "wishing people happyness". The "people" here refers to "the widest people" and "the longest people" instead of an individual. Therefore, it is in the highest level of design.[12]

\section{F. As Advanced Productivity and A Means of Production Management, Design Creates New Substances, Changes People's Life and Creates High Added Value of Commodities}

The influence of design on society is displayed in the two aspects of material and spirit. Design reflects human beings' spiritual culture value. Design works are spiritual objectification of designers. They carry out objectification of their talent and spirit and reflect their talent and spiritual personality fun through products. Products show everything of a designer. In terms of design production, design not only refers to product manufacturing, it also produces the subject of designer and great audience appreciating art.

Design is a commodity of mass production and it has physical property. Design's marketability contains value law of commodity. Design's fashionability shows science and technology level, a more ambient characteristic compared with painting and other artistic creations. Design is an important carrier of social economy and ideology. Mrs Thatcher, the former prime minister of UK once said: "Design is the fundamental thing of UK's industry future. If forgetting the importance of excellent design, UK's industry will never be competitive and never occupy the market. To some extent, industrial design is even more important than premier's work to UK."【13】 In 1980s, design industry injects great vitality into British industry. Some economy individuals think that "Japanese economy equals to designability". Japan is in short of resource. During 30 years after the war, Japan's average annual national economy grows at $10 \%$, which is unprecedented in human history of 6000 years. After the Second World War, due to terror of Nazi, many European national artists and designers flee to America. Thus, American art and design gradually develop after the Second World War and lead the world. Human history proves that design has been regarded as the fundamental strategy and efficient way to improve economic profit.

Commodity's high added value refers to function, material and sensitivity. The higher F. M. S. is, the higher added value is. Enterprise's CI design can also create high added value. Design's art connotation is the forever insurance to create high added value. After the second oil crisis, some modern products appear. They save energy and material. They are multi-functional, light, thin, short and mini. They are all high added value commodity creations. Competition of high added value commodity mainly depends on design competition.

Design is a means of production management, determining survival and development of enterprises. Design has infiltrated 
into every aspect of society and has close relation with a nation's economic construction and development. Design is the main factor of social and economic development strategy, influencing the whole society. Design is an important means to mould and promote enterprise's brand image. Design determines survival and development of enterprise. Design can effectively promote commodity sale.

The general principle of design is "practical, economical and beautiful". Of course, on the other hand, design should be able to improve competitiveness of commodity. Due to bad design or lack of design, many commodities not only consume manpower and material resources, but also are unsuitable with high cost. Therefore, they are not welcomed and are unsalable.

Design is creating new symbols. This kind of intelligent cultural creation activity is a kind of human's life management. Design is self decoration, which is born due to people, serves people, satisfies people's need, changes people's life and is the embodiment of advanced productivity creating high added value of commodities.

\section{REFERENCES}

[1] Li Yanzu's Art Design Introduction. Hubei Art Press, 2002 P1.

[2] Wang Shouzhi's Modern Design History of the World. China Youth Press, 2002

[3] Quoted from Jing Lei's Design Introduction. Hebei Art Press, 2007 P2.

[4] The same as [3]

[5] The same as [3]

[6] The same as [3]

[7] The same as [3]

[8] The same as [3]

[9] Modern Chinese Dictionary P1003 Commercial Press 1978.

[10] Come from Yin Dingbang's Design Introduction. Changsha: Hunan Science Press, March 2006.

[11] Clive Bell's(British) Art translated by Zhou Jinhuan and Ma Zhong. Chinese Literature and Art Joint Publishing Company, 1984.

[12] Zhang Haiying's People Oriented Design: Human Desire, Human Nature or Humanity? Master thesis of Wuhan University of Technology, 2010.

[13] Come from Yin Dingbang's Design Introduction. Changsha: Hunan Science Press, March 2006. 